\title{
CAFÉ FEMENINO: UNA MARCA Y UNA EXPERIENCIA DE AGROECOLOGÍA Y CIUDADANÍA
}

\author{
CAFÉ FEMENINO: A BRAND AND AN EXPERIENCE OF AGRO-ECOLOGY AND \\ CITIZENSHIP
}

\author{
${ }^{1}$ Julio Chávez-Achong
}

\begin{abstract}
Resumen
Se describe y analiza, desde la perspectiva de resiliencia socioecológica, el proceso organizativo del café orgánico en el distrito de La Florida y alrededores (provincia de San Miguel, departamento de Cajamarca, Perú), entre los años 1992 y 2013, tomando como referencia la experiencia del Café Femenino, una marca de café orgánico para la exportación. Esta experiencia tiene como actores principales a las mujeres cafetaleras de la asociación ASPRO, base de la Central de Cafetaleros del Norte-CECANOR, a la ONG CICAP, a la empresa comercializadora PROASSA y a la importadora estadounidense OPTCO. Con la descripción de los resultados y las conclusiones se quiere aportar elementos para una reflexión sobre la relación entre agricultura orgánica, relaciones interculturales y sustentabilidad.
\end{abstract}

Palabras clave: agroecología, asociaciones agrarias cafetaleras, café orgánico, café femenino, comercio justo, hibridación cultural, interculturalidad, resiliencia socioecológica, socioecosistema, sustentabilidad.

\begin{abstract}
The article describes and analyses, from the perspective of socio-ecological resilience, the organizational process of the organic coffee in the District of La Florida and surrounding area (province of San Miguel, Department of Cajamarca, Peru), between the years 1992 and 2013, with reference to the experience of the Café Femenino, a brand of organic coffee for export. This experience has as main actors: coffee women's Association ASPRO -base of the Central de Cafetaleros of North-CECANOR- the NGO CICAP, the marketing company PROASSA, and the American importing company OPTCO. The description of the results and conclusions attempt to provide elements for a reflection on the relationship between organic agriculture, intercultural relations and sustainability.
\end{abstract}

Key words: agro-ecology, coffee farming associations, cultural hybridity, fair trade, female coffee, interculturality, organic coffee, socio-ecological resilience, social-ecological system, sustainability.

\section{Introducción}

En el debate sobre el desarrollo sustentable, existe la necesidad de mostrar evidencias de que la insustentabilidad ambiental puede ser revertida, frenada o transformada en sustentabilidad debido a la intervención intencionada de actores sociales. La presente investigación quiere aportar elementos a esta reflexión, analizando información referida a la dinámica de un agroecosistemas con café orgánico de Perú articulado a la cadena internacional del Comercio Justo, a partir de estudios de caso. Se quiere examinar un proceso que incorpora el manejo del ecosistema, la producción, el procesamiento, la comercialización, la certificación orgánica y solidaria y el consumo del café orgánico articulados en una cadena de valor multiactor y multinivel.

¿Cuáles son las estrategias agroecológicas que mejor pueden contribuir a la creación de sustentabilidad? Para algunos autores, la opción más adecuada sería la recampesinización (regreso a sistemas de producción pre capitalistas, con relaciones mercado limitadas a los ámbitos locales) y la Soberanía Alimentaria, que elimina la dependencia externa a la agricultura industrial y limita el uso de combustibles fósiles en las cadenas largas de comercialización, que incrementan la emisión de gases de efecto invernadero (Altieri y Nicholls, 2012), (Sevilla y Soler, 2009) (Toledo, 2012).

¿Serán aplicables estas estrategias a todas las experiencias de producción orgánica? ¿Qué importancia podría tener en este debate el considerar situaciones en las cuales parecería que la interdependencia localglobal y la incorporación de la agricultura familiar a la modernización económica y social habría fomentado la resiliencia socioecológica local?

En la presente investigación se asume la noción de sustentabilidad desde el paradigma de la complejidad (Morin, 2011) (Ruiz y Solana, 2013), se propone como enfoque teórico de sustentabilidad el de la resiliencia socioecológica (Ruiz, 2013), y se identifica el socioecosistema, una expresión de la noción de sistema adaptativo complejo, como la unidad fundamental de observacióny análisis (Ríos-Osorio et al., 2012). Los socioecosistemas son acoplamientos dinámicos entre 
subsistemas sociales y ecológicos que interaccionan entre sí mediante procesos y flujos materiales y no materiales. Los sistemas sociales tienen como dominios la cultura, la economía, la política, las estructuras sociales, etc. Los sistemas ecológicos tienen como dominios la naturaleza independiente de la intervención humana y el medio ambiente socialmente construido. Desde esta noción, la sustentabilidad es asumida como una característica posible en la que (i) la vida humana pueda continuar indefinidamente, (ii) las individualidades humanas pueden prosperar, (iii) las culturas se pueden desarrollar en una forma tal que las actividades humanas no destruyan la diversidad, complejidad y función del soporte ecológico de la vida" (Constanza et al., 1991, en Salas- Zapata, 2012: 61). La resiliencia, desde una perspectiva socioecológica, la sumimos como "la capacidad de un socio ecosistema para sobreponerse a situaciones de crisis, recomponiéndose creativamente y consiguiendo mantener las características básicas que definen su especificidad" (Escalera, 2011:7).

Para el abordaje de las relaciones interculturales, se toma de García Canclini la siguiente aproximación: "entiendo por hibridación procesos socioculturales en los que estructuras o prácticas discretas, que existían en forma separada, se combinan para generar nuevas estructuras, objetos y prácticas. A su vez, cabe aclarar que las estructuras llamadas discretas fueron resultado de hibridaciones, por lo cual no pueden considerarse fuentes puras.” (García, 2001: 14). “Cómo fusiona la hibridación estructuras o prácticas sociales discretas para generar nuevas estructuras y nuevas prácticas? A veces esto ocurre de modo no planeado, o es resultado imprevisto de procesos migratorios, turísticos y de intercambio económico o comunicacional. Pero a menudo la hibridación surge de la creatividad individual y colectiva, no solo en las artes, sino en la vida cotidiana y en el desarrollo tecnológico." (García, 2001:17).

Con ese marco interpretativo, dos ideas básicas guiaron, a modo de hipótesis orientadoras, la investigación: 1) La inclusión de pequeños productores y campesinos cafetaleros en los sistemas del café orgánico y del comercio justo favorece la resiliencia socioecológica local al mejorar las capacidades de organización y de alianzas de los/las productores/as locales y al fomentar sistemas agroforestales; 2) La capacidad de la caficultura orgánica articulada al comercio justo para generar resiliciencia socioecológica local estaría asociada a la presencia de una visión agroecológica amplia y a un proceso de hibridación cultural.

Con la investigación se quiere encontrar elementos que ayuden a comprender cómo operan las relaciones sociales y culturales entre los actores de la cadena del café orgánico para el comercio justo, y como inciden en la resiliencia de socioecosistemas locales. Para ello se tuvo como objetivos específicos: 1) Describir el proceso socioproductivo de los/las cafetaleros orgánicos/as de una asociación vinculada al comercio justo, en su efecto sobre las condiciones de resiliencia del socioecosistema local, y, 2) Analizar los arreglos institucionales entre actores de la cadena del café orgánico para el comercio justo, caracterizando la trama de relaciones, valores, actitudes, comportamientos y concepciones con relación a la sustentabilidad.

\section{Métodología}

La estrategia de investigación seleccionada para este propósito es el estudio de caso, entendido, de modo general, como un estudio intensivo de situaciones y procesos específicos y acotados pero enmarcados en contextos mayores. Con el estudio de caso se quiere encontrar datos y referencias empíricas referidas a problemas teóricamente formulados.

Para el estudio del Café Femenino se ha procesado información directa en campo y mediante entrevistas, además de acceder a documentación interna de las instituciones CICAP y PROASSA. Una primera visita, realizada durante 5 días, en el mes de noviembre del 2012, tuvo un objetivo de reconocimiento y de primeros diálogos en dos zonas distintas (La Florida, en San Miguel, Cajamarca y Penachí, en Salas, Lambayeque). Se pudo conversar con directivos de las asociaciones ASPRO y ASPAPE, respectivamente, así como visitar predios cafetaleros y conocer a mujeres socias integrantes del Café Femenino. Ello permitió tener mejores criterios para la selección de la primera zona a estudiar. La segunda visita, en enero del 2013, consistió en una estancia de 20 días en la zona de La Florida, en ella se hizo observaciones en los predios, entrevistas a un grupo representativo de asociadas, a secretarias de la mujer, a inspectores internos, se realizó entrevistas a informantes clave y gente mayor de la comunidad, además de haber sido una experiencia de convivencia con familias de la zona. La información de campo más intensiva y extensiva proviene de esta visita. Finalmente, otra visita se realizó en el mes de mayo del año 2013 y tuvo como finalidad hacer entrevistas en profundidad a personas emblemáticas del campo y la ciudad asociadas a la experiencia del Café Femenino y presentar, en una reunión local, los primeros borradores de las conclusiones, recibiendo opiniones de distintos actores. Una versión de este informe fue presentado en el seminario internacional de SOCLA (IV), en agosto del año 2013, de donde se tomaron sugerencias. Se ha realizado observaciones directas y sistemáticas a lo largo de la casi toda la cadena del café: en los predios cafetaleros, en el centro de acopio de La Florida, en el local de CECANOR, en las oficinas de CICAP y PROASSA, en la empresa Industrial San Antonio donde se hace el procesamiento final y el embalaje para el embarque. Asimismo se ha visitado las bioferias de Lima, cafeterías de cafés especiales, la gran feria nacional ExpoCafé 2012 y 2013. Mediante cuestionarios remitidos por correo electrónico se ha recabado información de la entidad certificadora OCIA y de la empresa importadora estadounidense OPTCO. Asimismo se ha obtenido 
información documentaria y se ha realizado entrevistas a miembros del comercio justo en Perú: FLO y FLO-CERT.

\section{Resultados y discusión}

La zona de producción estudiada se ubica en la parte media de la Cuenca del Río Zaña (Paralelos $6^{\circ} 46^{\prime}$ y $7^{\circ} 06^{\prime}$ Latitud Sur y Meridianos $78^{\circ} 54^{\prime}$ y $79^{\circ} 44^{\prime}$ Longitud este), en la Yunga Marítima. La Zona de Vida es el Bosque Seco- Premontano Tropical. Una parte de la zona de producción corresponde a Bosque de neblina. La franja de cafetales está entre 1200-1800 msnm. Hasta los años 50s, las montañas de La Florida albergaban una variedad de flora y fauna características de las zonas subtropicales. Laurel (Cordia alliodora), roble (quercus robur L.), cedro (Cedrela Odorata), guabo (Inga spp), pajuro (Erythrina edulis) entre los árboles; leones, tigres, zorros, entre los mamíferos, pavas, pilcos, loros, entre las aves. Como frutales destacaban la granadilla (Passiflora liguralis) y el lúcumo (Pouteria lúcuma) y también otros frutos apreciados por las aves, como el tuple (Dunalia arborescens). Entre los árboles introducidos estaba la grevilea (Grevillea Robusta).

A partir de los años 50s se intensificó una colonización espontánea de las montañas de la cuenca del Zaña, inducida por la modernización de la Hacienda cafetalera Monte Seco, propiedad de la familia De la Piedra. Los colonos serranos, algunos de ellos trabajadores eventuales de la hacienda, fueron desbrozando el bosque e instalando cultivos de pan llevar (papa, yuca, camote, zanahoria, camote, arveja, frejol y plátano) y cultivos comerciales con fines de obtener ingresos monetarios. Entre los cultivos comerciales estuvo primeramente la caña para la producción de aguardiente con destino a los mercados locales de la sierra norteña; luego la caña fue reemplazada por el café. En la zona, la especie difundida fue arábica y la variedad, típica.

Las familias ralearon pero no eliminaron el bosque, creando un sistema agroforestal no tecnificado con predominio de la asociación café/plátano, acompañada de frutales (naranjo, lúcumo, chirimoya) más una cubierta parcial de árboles que le daban sombra. En la segunda mitad del siglo XX la población rural fue agrupándose en pequeños caseríos. Los nombres de estos caseríos no revelan una identidad cultural originaria sino una caracterización del hábitat natural: Agua Azul, Montaña de Séquez, Pampa de Séquez, Limoncito, La Laja, La Granadilla, El Naranjo.

\section{EL CAFÉ ORGÁNICO EN LA FLORIDA}

Durante la Reforma Agraria, en los años 70s, las tierras de la hacienda Monte Seco se transfirieron a sus trabajadores estables. Con el modelo de cooperativa, en Monte Seco se consolidaron derechos sociales pre existentes, como el seguro social y el asalaramiento de la fuerza de trabajo. Sin embargo, la cooperativa fracasó como modelo de empresa económica desapareciendo a inicios del los años 90s. Ello dejó un vacío en la vida local, facilitando el control de los intermediarios privados sobre las economías familiares. Motivados por los beneficios del sistema de cuotas internacionales que duró hasta 1987, en La Florida se formaron cooperativas de servicios de comercialización, la mayoría de ellas conducidas por transportistas y comerciantes intermediarios.

Las oscilaciones de los precios internacionales del café desestabilizó la economía familiar cafetalera. Una reacción de los productores cafetaleros individuales de La Florida fue la formación de cooperativas de servicios para la comercialización conjunta de sus productos, tratando de colocar su café directamente en las tiendas de los exportadores nacionales. Sin embargo, diversos factores, como la inexperiencia, la falta de liderazgo, entre otros, impidieron que este intento fructificara. Las familias cafetaleras en esos años mantuvieron sus rasgos de unidades productivas de subsistencia. Cuando los precios del café bajaban, podían eliminar sus cafetos para ampliar cultivos de pan llevar y vender la madera de los árboles.

La alternativa de la producción orgánica llegó a La Florida en los inicios de los años 90s. Fue promovida por un grupo profesional constituido como organización no gubernamental: el CICAP, Durante los años 80s CICAP había trabajado en el fortalecimiento de sindicatos de las cooperativas cañeras de la costa, lo que a su vez recogía tanto la experiencia política como las relaciones de sus miembros fundadores. Cuando este grupo llega a La Florida, ya había tenido algunos cambios en sus concepciones de manera que los temas ambientales y la preocupación por la comercialización eran parte de su agenda.

En el año 1992 ocurrió una de los mayores descensos de precios del café llegando a pagarse tan solo US \$ 45/qq en el mercado internacional o alrededor de $\mathrm{S} / 70 \mathrm{u} \mathrm{S} / 80$ en la zona, por lo que una parte de las familias cafetaleras, ante los bajísimos precios, querían sustituir sus cafetales, y con ello la cobertura forestal. El CICAP había iniciado en el año 1992, con influencia temática de la cooperación privada alemana, un proyecto para favorecer los cultivos orgánicos y la salud y seguridad alimentaria de la población de La Florida. Tenía previsto que recién al tercer año del proyecto se iniciaría una experiencia de comercialización. Sin embargo, la presión de los cafetaleros decidió a sus directivos ingresar en el año 1992 a la comercialización directa al exterior tratando de salirse de la intermediación privada, que en esa época estaba articulada a la empresa exportadora de café más importante del Perú, dominada por el grupo PERHUSA. El CICAP había contactado con importadores internacionales y contaba con compromisos de venta. Es entonces que, adelantando fases de su proyecto, inicia su labor de intermediación sin fines de lucro, asegurando precios de venta mayores al de los comerciantes locales gracias al sobre precio de los productos orgánicos (Por acuerdo entre las tostadoras e importadoras norteamericanas, el café orgánico recibía 
una prima de US\$ 30 pagados por los tostadoras a los importadores y transferidos por estos a los productores locales). El financiamiento de la ONG por la cooperación alemana permitía a CICAP no cargar sus costos al proceso de comercialización, redundando todo ello en beneficios para los agricultores.

En el año 1994, una oscilación brusca en un solo mes en el mercado internacional, dominado por las grandes tostadoras, (cae de US\$ 240 /qq a US\$ 100/qq) termina estoqueando de bolsas de café a CICAP adquiridas previamente a los campesinos al precio más alto pero sin poder venderlo a un precio similar. El importador norteamericano, entonces una pequeña empresa naciente, que además recién empezaba su experiencia en Latinoamérica, tampoco en esas condiciones honra el contrato, aunque plantea una acción de alianza a CICAP para revertir progresivamente el hecho. Producto de ello CICAP termina vendiendo sus stocks a otra empresa perdiendo alrededor de US \$ 100 por qq. El CICAP entra en grave déficit, debe hipotecar bienes, pues si, por un lado, debió cancelar en el corto plazo a los agricultores como se había comprometido, por otro lado no pudo realizar la venta del café en el precio proyectado. En el año 1995, y por recomendación de la cooperación alemana, CICAP crea una empresa comercializadora autónoma de la ONG, de nombre Promotora de Agricultura Sostenible SA, PROASSA, que funcionaría con reglas propias de una gestión económica empresarial, aunque con fines sociales.

Entre los años 1993 y 1999, la producción del café orgánico de La Florida encontró un mercado en los Estados Unidos gracias a la intermediación, primero de CICAP y, luego, de PROASSA. Después de la crisis de precios del año 1994, la empresa importadora OPTCO fue colocando poco a poco el café en los mercados internacionales. A su vez, la comercializadora PROASSA, autonomizada -aunque no independizada- de la ONG CICAP, mejoró su capacidad de gestión, por lo que no sólo pudo pagar la hipoteca del local de CICAP sino generar un plus comercial.

Entre los años 1995 y 1999 el café orgánico es difundido por PROASSA en otras localidades norandinas. En cada lugar se fueron formando comités y asociaciones de productores orgánicos y otros grupos en transición a la producción orgánica. Sin embargo, los costos de la certificación orgánica expedida por entidades privadas, eran elevados. A partir del año 2000, y luego de un trabajo de organización muy intenso, PROASSA y las asociaciones locales de cafetaleros orgánicos constituyen la central CECANOR, y consiguen que se les reconozca la certificación orgánica única, disminuyendo sus costos unitarios. Con esta organización constituida, PROASSA obtiene la Certificación del Comercio Justo y logra la exportación de 3 contenedores de café (todo en un mismo año).

Con la certificación del Comercio Justo, PROASSACECANOR pudieron llevar el café del nororiente a nuevos mercados, siempre con el impulso y la intermediación de la importadora OPTCO. El comercio justo añadió otra prima: la prima social. Así, el café vendido recibía: el precio por quintal de café en la bolsa de New York (al momento de la venta) + una prima orgánica de US\$ 30/ qq + una prima social de US\$ 20/qq. El comercio justo añadió otro beneficio: el precio mínimo solidario de US \$ 140/qq. aún cuando los precios internacionales, medidos por la bolsa de New York, fuesen menores.

Entre los años 2000 y 2005, años en que las oscilaciones de precios internacionales de café llegaron nuevamente a sus mínimos históricos (sobre todo en el año 2002, en que bajó hasta US \$45/qq), contrariamente a lo que sucedía a los cafetaleros no orgánicos, subsumidos en la red de intermediarios privados, a los cafetaleros orgánicos se les aseguró precios mínimos y mercado seguro. Estos fueron los años de mayor afiliación de productores orgánicos y no orgánicos en transición en La Florida y en todas las zonas con presencia de CECANOR (Lambayeque, Amazonas, San Martín).

En ese contexto, en el año 2004 se crea la marca Café Femenino, a propuesta de las empresas de comercialización y de importación, buscando llegar a un nicho especial de mercado. Para ser partícipe de la marca se tenía como exigencia que la producción sea orgánica y proveniente del trabajo de las mujeres en parcelas de su propiedad. Sea por herencia de sus padres o por decisión de los maridos de ceder alguna de sus parcelas a su pareja, las mujeres se hicieron propietarias de parcelas en extensiones entre 1 y 1.5 ha., salvo excepciones con hasta 3.5 ha. La producción y exportación del café Femenino se premiaría con una prima de US\$ 2/qq. Una diferencia cualitativa tendría esta prima respecto de las anteriores: mientras que el pago de las primas por ser café orgánico y por ser del comercio justo se entregaba a las organizaciones para su funcionamiento, la prima por café femenino se entregaba directamente a las mujeres cafetaleras, en libre disposición.

Por otro lado, tostadores e importadores norteamericanos convinieron en crear un fondo, aportado por los tostadores, para financiar la creación de la Fundación del Café Femenino, la misma que con ese y otros recursos apoyaría proyectos dirigidos a favorecer la alimentación y capacitación de las mujeres cafetaleras organizadas. Este esquema de primas, pagos y posibilidades de proyectos sociales rige hasta hoy.

En el año 2013, por iniciativa de PROASSA, las delegadas de las mujeres del café femenino de diferentes zonas acaban de constituir una organización para gestionar y difundir el Café Femenino, siendo parte de CECANOR.

La comercialización interna del café está a cargo de CECANOR. La comercialización externa, es decir la venta del café al importador OPTCO (única empresa compradora) la realizan CECANOR y PROASSA. Pero en el caso del Café Femenino, quien comercializa externamente es PROASSA. La Fundación del Café Femenino, de los Estados Unidos, ha financiado 
pequeños proyectos de las mujeres cafetaleras, como proyectos de cocinas mejoradas, de capacitación en salud y alimentación, de introducción de cereales andinos etc., con fines principalmente de autoconsumo familiar, indistintamente a través de CICAP o de CECANORPROASSA. Como aproximación cuantitativa se tiene que en el año 2012, solo en La Florida, CECANOR compró y pagó café orgánico de sus asociados/as -de un total de 152 socios, 65 eran mujeres- por un monto de S/. 230 mil (aprox. US \$ 85 mil). El total de compras por café orgánico de CECANOR ese año ascendió a S/. 1 millón 864 mil, (alrededor de US \$ 690 mil)

ASPRO cuenta con un local propio en La Florida, donde se reúne su directiva, se realizan capacitaciones, se alquila o presta a otras instituciones sea del sector privado o del Estado, como entidades de salud y educación. El local es una referencia en la ciudad. Es allí donde se acopia el café de los comités, se mide la humedad, se registra el peso, se firman los compromisos de pago, que luego serán confirmados previa una nueva medición en la planta de Chiclayo.

Internamente, CECANOR tiene instancias varias para garantizar el cumplimiento de las normas orgánicas y del comercio justo. Hay un sistema de inspección interna constituido por agricultores que se capacitan especializadamente para las visitas de evaluación y monitoreo de todas las parcelas de los/las asociados/ as. Este sistema es una de las exigencias de las normas internacionales. También existen promotores encargados de colaborar con los/las asociados/as en el conocimiento de las normas, en el llenado de los registros y en todo cuanto se requiera para garantizar la calidad de la producción y el correcto manejo de las variables de la producción orgánica y la organización agraria. En general, exceptuando las actividades de comercialización externa, CECANOR tiene una dinámica descentralizada.

Una vez al año, hay dos inspecciones externas: la inspección orgánica a cargo de una certificadora privada (OCIA), y la del comercio justo, por FLO. Por otra parte, la institucionalidad de la experiencia relatada, incluyendo al Café Femenino, recae en una alianza de los siguientes actores: CECANOR-PROASSA(antes CICAP) y OPTCO. Este es el núcleo del proceso. PROASSA, además de haber cumplido y seguir cumpliendo el rol de agente comercial, y por lo tanto ser el eje de ese núcleo, asume un rol de liderazgo sobre el conjunto del proceso.

Los dos momentos más críticos que han vivido los cafetaleros orgánicos de esta experiencia, han sido: la caída de los precios del año 1994, que pudo determinar el cese del proyecto con el que se iniciaba la experiencia, y los problemas internos que determinaron la salida de algunos dirigentes y comités de la organización, por diferencias respecto de grados de autonomía/ independencia de CECANOR y PROASSA, una tensión en parte motivada por cómo reaccionar ante la presión de intermediarios locales en condiciones de bonanza en los precios.
Este último problema organizativo tiene una base económica derivada del desenvolvimiento de la economía de mercado y de la especulación: cuando los precios internacionales del café, medidos por los precios de la bolsa de New York, son muy altos, entonces los precios que ofrece CECANOR a sus asociados/as no guardan mucha diferencia con lo que ofrecen los comerciantes privados. La diferencia proveniente de las primas puede ser absorbida fácilmente por estos para pagar precios mayores que CECANOR a algunos productores. Los productores, que ven los movimientos de cortísimo plazo y tienen necesidades perentorias, podrían eventualmente preferir vender a los intermediarios y verse tentados a incumplir con su organización, que al fin de cuentas también trae consigo exigencias de trabajo, de tiempo y presiona al cumplimiento de acuerdos colectivos que pueden ser una carga al ya exigente trabajo productivo. Los intermediarios no asumen ningún costo de organización y lo que retribuyen por su café a algunos cafetaleros puede ser recuperado con los pagos más altos que obligan a otros productores. Mientras tanto la información sobre los mejores precios del particular llega a los asociados creando zozobra. En esos momentos, cualquier tensión en la organización puede incidir en la existencia de la alianza. En esas condiciones es explicable que una prédica del tipo "nosotros lo hacemos solos sin necesidad de la comercializadora PROASSA" puede ser muy convincente para justificar propuestas organizativas independientes de los productores o también comportamientos "free riders". Sin embargo, durante 11 años el número de asociados se ha mantenido y se ha ampliado el mercado interno (nacional) y externo para la producción orgánica y de comercio justo, habiendo surgido una marca, el Café Femenino, en torno a la cual un grupo de mujeres cuenta con activos propios, se ejercita en su liderazgo y adquiere presencia pública de modo tal que en las últimas elecciones las agrupaciones políticas las buscan para ocupar las listas electorales para cubrir el cupo obligatorio de $30 \%$ de mujeres candidatas que exige la ley.

Sólo una mínima parte del Café Femenino se tuesta en Chiclayo y se comercializa en el mercado nacional, vía pequeñas bioferias. Recientemente el Café Femenino empieza a ofrecerse en algunas cafeterías que ofrecen cafés especiales (gourmet, orgánico, ecológico, amigos de las aves, etc.).

Una competencia posible de la caficultura orgánica en La Florida podría ser la propagación del cultivo de bambú o caña de Guayaquil, que se utiliza en la construcción, y que actualmente tiene precios crecientes en el mercado nacional. Una amenaza es el cambio climático expresado en el incremento de en la humedad pero en otros momentos de las temperaturas. Se registra mayor duración de las bajas neblinas, fenómeno que incide en la caída de los frutos. 


\section{LAS MUJERES DEL CAFÉ FEMENINO, DE LA FLORIDA}

Las mujeres asociadas para la marca Café Femenino son, en su mayoría, descendientes en primera o segunda generación, de migrantes andinos. Desde niñas trabajaron en la agricultura. Las personas mayores de 60 años o no tienen ningún nivel de educación o tienen máximo hasta primaria completa. Las socias con $30-40$ años, tienen secundaria completa. No hay personas con educación superior. El territorio que habitaron durante su vida es la zona de residencia y localidades cercanas. La experiencia de vida es exclusivamente rural. Tienen una trayectoria de compromiso con la agricultura orgánica desde los años 90s., antes de asociarse para la marca Café Femenino. El móvil principal para participar en el Café Femenino ha sido la oportunidad de un plus en el ingreso económico monetario, pero también la confianza en el proceso organizativo. No han sufrido resistencia familiar a integrar Café Femenino. En muchos casos fueron alentadas por sus maridos o sus padres. La parcela propia fue transferida por el marido o recibida en herencia. El tamaño de las parcelas es de 1-1.5 ha., salvo excepciones que podrían llegar a 3.5 ha. El proceso productivo depende exclusivamente del régimen natural de lluvias.

Las mujeres del café orgánico no solo conservan pautas alimentarias de sus padres y abuelos, también están densificando la producción de alimentos orgánicos al instalar cultivos como la quinua y hortalizas en sus parcelas, con efecto en la seguridad alimentaria.

La parcela de café tiene tres estratos muy definidos: una cobertura arbórea alta cuya finalidad principal es dar sombra y aportar a la fertilización natural del suelo; un nivel más bajo con árboles frutales y arbustos, como plátanos, naranjos, chirimoyas, granadillas, etc. En medio de ellos crece el café. En una sección aparte las socias tienen instalados plantas de bambú. En 1 Ha. existen entre 2,000 y 3,000 plantas de café. Cada planta de café produce 1 a $2 \mathrm{~kg}$./año. Cada cosecha/año, dependiendo de diversos factores, las mujeres venden 5 a 10 quintales Algunas han llegado a 13 - 15/qq/año, pero es excepcional. La producción del café es casi en su totalidad para la venta. Una muy pequeña parte del producto queda para el consumo familiar.

Las mujeres del Café femenino identifican el concepto de agricultura orgánico como: asociación de árboles y plantas, no uso de pesticidas y agroquímicos, tener terrenos limpios de desechos tóxicos, el abono con guano de cuy, compost y biol, el manejo de las semillas para tener plantones de café de buena calidad. Identifican el nombre de Café Femenino con el hecho de que es producido por mujeres. Solo algunas hacen explícito una mayor igualdad entre hombres y mujeres; algunas mujeres mencionan que las mujeres tienen más dedicación y gusto que los hombres cuando trabajan el café. Las socias expresan satisfacción por ser capacitadas, dicen que el café que producen es aromático y de exquisito sabor en comparación al de la Selva. Expresan orgullo por exportar y ser reconocidas en otros países. El conocimiento de la cadena de comercialización es incompleto, para muchas termina en el lugar de la entrega en La Florida o en la planta de Chiclayo. El conocimiento de lo que ocurre externamente al Perú es muy elemental o difuso. Sin embargo sí están enteradas de los precios internacionales a través de las emisoras radiales. También reciben información directa de lo que sucede en el mercado internacional cuando reciben visitas de los dueños de la importadora OPTCO.

El consumo familiar de alimentos depende principalmente de la producción propia(familiar), consistente básicamente en plátano, yuca, hortalizas, en algunas ocasiones de los animales (aves, cuyes y, excepcionalmente, cerdos) y queso. El consumo de arroz y fideos ya es parte de la dieta de la familia campesina, que junto con el aceite, el azúcar, la sal, etc., se compran en la feria dominical en la capital de La Florida. Los alimentos se siguen preparando en cocinas de leña. El premio por ser Café Femenino se gasta en pagar a peones temporales (incluidos familiares), en gastos de salud y de alimentación. Es un monto módico (US \$ 20-30/campaña/año), pero con impacto simbólico.

\section{Conclusiones}

El Café Orgánico ha sido una alternativa de producción agroforestal en las laderas, pampas y partes bajas de las montañas de La Florida, frenando la deforestación.

La organización actual de los/las cafetaleros/as ha surgido como reacción a los intermediarios privados y se ha modelado en torno a las exigencias de calidad del mercado orgánico, pero también expresa principios de vida solidaria de la comunidad.

La opción por la agricultura orgánica promovida por grupos profesionales de la región, la alianza amplia de actores y el aprovechamiento del marco institucional de la producción orgánica y del comercio justo, han sido factores favorables para enfrentar amenazas externas (la crisis de precios) y debilidades internas (las tendencias a la división de la organización) y han favorecido atributos ecológicos del agroecosistema, es decir, emergieron atributos de resiliencia socioecológica.

El proceso muestra que ha ocurrido una complementariedad entre la cultura campesina de trabajo y organización local, (aunque sin fuertes identidades de tipo étnico como en otras regiones de Perú), y una cultura cosmopolita, sea en la versión de valores solidarios de la cooperación al desarrollo y del comercio justo o de los valores ambientales y postulados sociales del movimiento agroecológico peruano.

El Café Femenino ha sido una experiencia que ha contribuido a la ciudadanía de las mujeres, expresada en una mayor autoestima y empoderamiento, en el reconocimiento de derechos a poseer activos productivos, la aceptación social a sus cargos y al aporte de liderazgo. Las mujeres adquieren presencia pública y ganan espacios de decisión en sus hogares y en la vida comunal. Este 
proceso se enhebra con su rol en la seguridad alimentaria apoyada por la agricultura ecológica. Sin embargo, no se aprecia que se haya asumido explícitamente un enfoque de género. Las mujeres que no son líderes tienen una visión localista de su organización.

Las familias dedicadas al café orgánico están capitalizando sus fincas. Un gasto de gran estimación es el ejecutado en la educación de los/las hijos/as, que es un aporte específico de las mujeres en las decisiones familiares.

No se observa que haya surgido un movimiento ambientalista asociado al café. El tema de los precios, premios y primas sigue predominando como justificación para el compromiso de los/las productores/as con el Café Orgánico, elCaféFemeninoy la organización consiguiente. De modo aproximativo, se puede afirmar que los/las productores/as se están convirtiendo en Caficultores/as en la medida que las actividades productivas se refuerzan conscientemente con valores específicos (el aprecio por lo natural y limpio, por la seguridad alimentaria, por la importancia del trabajo más intensivo, etc.), se ejercen nuevos derechos (a la propiedad de la tierra por parte de las mujeres, a la comercialización directa, a la organización, a la opinión, etc.); asimismo se construye tejido social y se va transformando la situación de las mujeres hacia una relación de mayor igualdad dentro de las familias y en la vida organizativa. Se observa liderazgo de las mujeres en la organización campesina.

Aunque en la experiencia del Café Orgánico y del Café Femenino en La Florida puede observarse respeto, colaboración, proyectos económicos comunes, lazos de amistades entre actores, y una fuerte asociación entre saberes tradicionales y modernos de la agricultura orgánica, también es evidente que hay asimetrías en la gestión de la cadena en el plano internacional, en el predominio de normas estandarizadas que viniendo de fuera no siempre toman en cuenta algunas características locales Se puede afirmar que hay relaciones interculturales pero no propiamente un diálogo intercultural.

Las relaciones interculturales han reafirmado algunos valores morales tradicionales (trabajo familiar solidario, responsabilidad personal, identidad local) y han introducido nuevos valores modernos (transparencia, eficiencia, competitividad). Se reconocen nuevas capacidades: asociatividad para el mercado, saber medir y registrar, saber negociar y gestionar, saber escuchar y valorar a las mujeres. Todo ello permitió nuevos conocimientos sobre el proceso económico general, especialmente en los varones.

La agroecología, como teoría y como práctica, no ha sido en La Florida un sustento para la recampesinización hacia una economía local y de retorno a formas de organización y producción pre modernas. Más bien ha incidido en una mayor articulación de las unidades familiares campesinas al comercio internacional, respetando formas productivas tradicionales agroforestales, pero tecnificándolas mediante exigencias de calidad derivadas del consumo ecológico moderno, pero que también se insertan en una cultura campesina que valora la responsabilidad con el cuidado de la vida. El Café Orgánico y el Café Femenino articulan actores de diferentes culturas dentro de un sistema económico global. Mercado y solidaridad, tradición y modernidad, términos aparentemente opuestos, se mezclan e hibridan.

\section{Agradecimientos}

Agradezco, en primer lugar, al Dr. Manuel Jiménez Sánchez, de la Maestría de Investigación Social Aplicada al Medio Ambiente, en la Universidad Pablo de Olavide (UPO), de Sevilla, tutor de mi TFM sobre hibridación cultural y resiliencia socioecológica en la cadena del café orgánico. El presente artículo deriva del trabajo final para la obtención del título de Máster, con su precisa dirección. El tema de investigación continúa en mis estudios actuales del doctorado en Medio Ambiente y Sociedad, de la UPO. Agradezco a las instituciones PROASSA y CICAP por su acogida al proyecto de investigación y a la discusión de los borradores de informe, a PROASSA por su apoyo permanente para la observación documentaria y la labor en campo, muy especialmente a la Sra. Isabel Uriarte de quien he recibido su total disposición para la obtención de la información, los contactos en la zona de estudio y para brindarme su gran conocimiento. Agradezco de sobremanera a las mujeres del Café Femenino que me brindaron su tiempo y compartieron sus profundos conocimientos, con especial reconocimiento a la Sra. Sabina Hernández y a la Srta. Lily Leiva, similar reconocimiento extiendo a los líderes, promotores e inspectores internos de ASPRO, especialmente a los Sres. Elbert Valenzuela, César Becerra y Octavio Torres. Del mismo modo, mi agradecimiento al proyecto VLIR UOSUNALM, cuyo subproyecto P3, coordinado por los Drs. Marc Craps y Gustavo Gutiérrez, me recibiera y financiara la labor de campo. El interés por el tema de estudio surgió de las conversaciones de café en el Mercado Saludable de La Molina, gracias a la inspiradora atención de mi amiga Antonieta Manrique.

\section{Literatura citada}

Altieri, M, y Nicholls, C. 2012. Agroecología: única esperanza para la soberanía alimentaria y la resiliencia socioecológica. www.agroeco.org/socla

Escalera, J. 2011. Coor. Consumir naturaleza. Productos turísticos y espacios protegidos en Andalucía. Sevilla: Aconcagua Libros.

García, C. 2001. Culturas hibridas. Estrategias para entrar y salir de la modernidad. Buenos Aires: Paídós, $1^{\mathrm{a}}$. Edición actualizada.

Ríos-Osorio, L. A.; Del Castillo, J. Á. \& Zapata, W. A. S. 2012. Bases conceptuales para una clasificación de los sistemas socioecológicos de la investigación en sostenibilidad. Revista Lasallista de Investigación, 8(2).

Ruíz, B. E. \& Solana, R. J. L. 2013. Complejidad y Ciencias sociales. 
Ruiz, B. E. 2013. Socioecosistemas y resiliencia socio-ecológica. Una aproximación compleja al medio ambiente. Ruíz Ballesteros, E., \& Solana Ruíz, J. L. (2013). Complejidad y Ciencias sociales.

Salas-Zapata, W. A., Ríos-Osorio, L. A., \& Álvarez del Castillo, J. 2011. La ciencia emergente de la sustentabilidad: de la práctica científica hacia la constitución de una ciencia.

Salas-Zapata, W. A. 2012. Diseño de un modelo de análisis de sostenibilidad de políticas públicas en salud.

Sevilla, E. y Soler, M. 2009. Del desarrollo rural a la agroecología. Hacia un paradigma de cambio. Revista de Estudios Sociales y Sociología Aplicada: 23-39. http:// europa.sim.ucm.es/compludoc/AA?articuloId=735296.

Toledo, V., et al. 2002. La Modernización rural de México: un análisis sociológico: 33-47. México.

\section{$\underline{\text { Siglas }}$}

ASPRO: Asociación de Productores Orgánicos. Organización base de CECANOR, en La Florida, Cajamarca.

CECANOR: Central de Cafetaleros del Nor Oriente. Asociación de productores de café.

CICAP: Centro de investigación, capacitación, asesoría y promoción (ONG)

FAIRTRADE: Sistema del comercio justo y sello certificador del mismo

FLO: Organización internacional del Comercio Justo

FLO-CERT: Empresa independiente encargada de la certificación para el comercio justo

INEI: Instituto Nacional de Estadísticas e Información (de Perú).

ICO: Organización Internacional del Café

IFOAM: Federación Internacional de Movimientos de Agricultura Orgánica

OCIA: Organic crop improvement Association. Empresa de certificación orgánica.

OPTCO: Organic Products Trading Company. Importadora USA de café certificado

orgánico

PROASSA: Promotora de Agricultura Sustentable S.A

SENASA: Servicio Nacional de Sanidad Agraria (de Perú).

SOCLA: Sociedad Científica Latinoamerica de Agroecología 